\title{
WRF simulations against sodar measurements of extreme winds and local breeze circulations serial events
}

\author{
Damyan Yanchev Barantiev ${ }^{1}$, Hristina Ivanova Kirova ${ }^{2}$, and Orlin Angelov Gueorguiev ${ }^{2}$ \\ ${ }^{1}$ Climate, Atmosphere and Water Research Institute at Bulgarian Academy of Sciences (CAWRI-BAS), \\ Sofia, 1784, Bulgaria \\ ${ }^{2}$ National Institute of Meteorology and Hydrology (NIMH), Sofia, 1784, Bulgaria \\ Correspondence: Damyan Yanchev Barantiev (dbarantiev@cawri.bas.bg)
}

Received: 24 February 2020 - Revised: 26 May 2020 - Accepted: 12 June 2020 - Published: 29 June 2020

\begin{abstract}
Forty percent of the world's population live within $100 \mathrm{~km}$ of the coastal line. Coastal zones are changing because of the interaction between the oceans and the land as well as human activities. The processes in coastal Atmospheric Boundary Layer (ABL) have being continuously studied as they are important for the ecosystems, recreational activities, fishery, economics and renewable energy resources. Remote sensing (RS) measurements of the ABL have being performed with sodar at Ahtopol synoptic station (Southeast Bulgaria) since 2008. The Intergovernmental Panel on Climate Change (IPCC) criteria for "rare" events have been applied to the period August 2008-October 2016 of the RS measurements and a reference extreme wind speed profile has been obtained. In this study, we test the ability of the Weather Research and Forecasting (WRF) model with Mellor-Yamada-Janjic ABL scheme to simulate extreme wind events, followed by sea breeze. As a measure of the ability of the used model configuration to reproduce the spatial and temporal structure of these complex weather situations some basic statistical metrics has been used. The results have shown relatively good agreement between measured and modeled wind speed but the sea breeze development has not been reproduced by the model.
\end{abstract}

\section{Experimental site and equipment}

The Experimental polygon (EP) Ahtopol is the southernmost synoptic station of the Bulgarian national weather service. The polygon is located at the southeastern Bulgarian Black Sea coast (about $400 \mathrm{~m}$ inland and $30 \mathrm{~m}$ a.s.l. - above the sea level) $2 \mathrm{~km}$ south-east of the town of Ahtopol. The coast line stretches out from NW to SE (with a steep about $10 \mathrm{~m}$ ). High spatial and temporal resolution measurements of wind and turbulence parameters (data of $20 \mathrm{~min}$ running average at every $10 \mathrm{~min}$ with $10 \mathrm{~m}$ vertical resolution) with monostatic Doppler sounding system (SCINTEC Sodar MFAS) have been started in summer 2008 at the EP Ahtopol. The maximum vertical range of the sodar is $1000 \mathrm{~m}$ but the effective range depends on the spatial and temporal resolution setup. The sodar range also depends on the reflected sound waves from the constantly changing turbulent inhomogeneities in the atmosphere, taking into account the pulsations of the amplitude and phase of the sound waves, there- fore the sodar data availability varies with height. The sodar measurements reveal the vertical structure of the coastal ABL and the acoustic data has been used for climatological studies in this region (Barantiev et al., 2011, 2013, 2017; Novitsky et al., 2012). Considering the reliability of this instrument and its capabilities to obtain wind field and turbulent parameters within ABL, it is useful tool for the numerical weather prediction (NWP) model performance evaluation (Kirova et al., 2018; Barantiev et al., 2019).

The Doppler effect techniques used in sodars and lidars are powerful method for wind energy production estimates as these RS instruments provide flexibility, accurate and precise data and are cost efficient. In particular, their capabilities are also used to detect extreme wind events for safely back to renewable energy absorption and prevention from significant damage on wind energy infrastructures caused from excessive loads on wind turbine components (Petrović and Bottasso, 2014). That in cases where measurements are not available it is important to have a reliable NWP model not 
Table 1. Model parameters and schemes used in this study.

\begin{tabular}{llll}
\hline Map projection & Lambert (centered at $42.084^{\circ} \mathrm{N}$ and $\left.27.951^{\circ} \mathrm{E}\right)$ & microphysics & $10=$ Morrison $2-$ moment scheme \\
\hline Domains & $\begin{array}{l}\text { horizontal grid space } 25,5 \text { and } 1 \mathrm{~km} \text {; number of grid points } \\
26 \times 21,36 \times 36,111 \times 111\end{array}$ & lw radiation & $\begin{array}{l}\text { 1= RRTM: Rapid Radiative } \\
\text { Transfer Model }\end{array}$ \\
\hline Model top & $50 \mathrm{hPa}$ & sw radiation & $2=$ Goddard \\
\hline Vertical levels & 42 & surface layer & 2 Eta similarity \\
\hline Spin up & $10 \mathrm{~h}$ & land surface & 2 Noah LSM \\
\hline ABL & $2=$ MYJ Mellor-Yamada-Janjic TKE & cumulus convection & 5 (D1 and D2) $=$ Grell3D \\
\hline
\end{tabular}

(a)

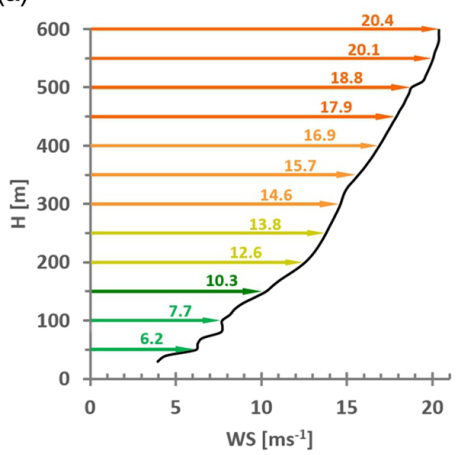

(b)

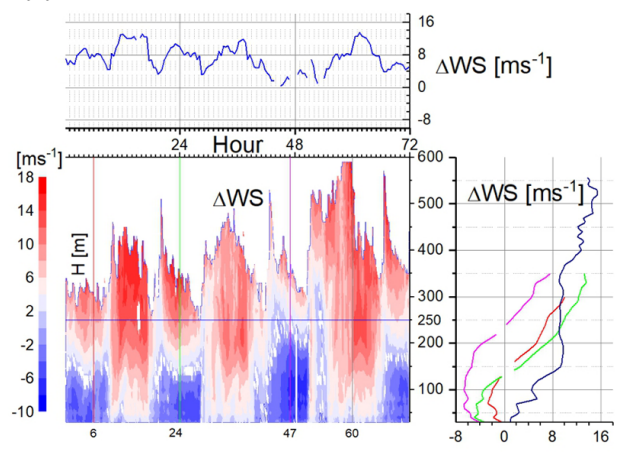

(c)

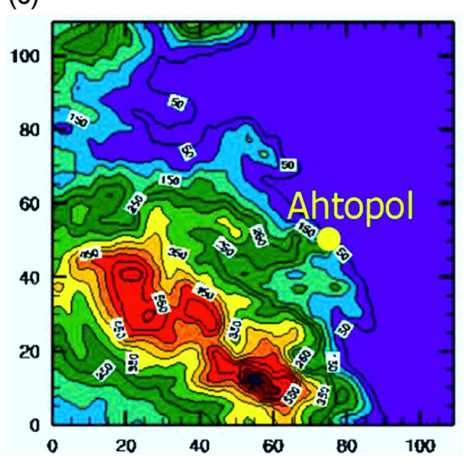

Figure 1. Reference extreme WS profile (a); $\Delta$ WS - difference between REWSP and observed WS during 17-19 March 2012 (b), profiles with extreme WS (red: 17 March - 06:00 EEST, green: 18 March - 00:00 EEST and violet: 18 March - 23:00 EEST line), during SB - black line, the blue line shows the profile at $250 \mathrm{~m}$; model topography of the innermost domain (c).

only for identification but as well as for prediction of extreme wind events. Remote sensing technology is developing fast during last decade allowing high resolution data from sodars and lidars and thus long-term studies and thorough evaluation of numerical models (Gryning et al., 2014, 2016). Such continuous observation data are important for studies of internal boundary layers, breeze circulation and air pollution in coastal areas which were possible only during short-term experiments 20 years ago (Batchvarova and Gryning, 1998).

\section{Methods}

Based on the sodar data at EP Ahtopol collected in the period August 2008-October 2016 (341971 data sets - correspond to $78.8 \%$ interval coverage) a reference extreme wind speed profile (REWSP) has been obtained in the framework of the project REPLICA (extReme Events and wind ProfiLe In a Coastal Area). The REWSP is defined as the 90th percentile of the Weibull wind speed distribution for data up to $600 \mathrm{~m}$ (Fig. 1a), based on the criteria for "rare" events of the Intergovernmental Panel on Climate Change (IPCC, 2011). The "extreme winds" data (about $3.17 \%$ from all measurements) comprises all profiles which are equal or exceed the REWSP values and with duration of the extreme event of $4 \mathrm{~h}$ at least.
The period 17-19 March 2012 from the extreme winds data base is presented in this study. The selected period is characterized with SW flow with recorded extreme winds and includes 3 sea breeze cells within the sodar range (Fig. 2a). The studied case is simulated with Weather Research and Forecasting (WRF) model (Skamarock et al., 2008), initialized with US National Center for Environmental Prediction Final Analyses (FNL) with $1 \mathrm{~km}$ spatial and $6 \mathrm{~h}$ temporal resolution. The numerical simulation is performed on the Supercomputer System "AVITOHOL" at Institute of Information and Communication Technologies - BAS (Atanassov et al., 2016). Model parameters and schemes used in this study are listed in Table 1. The choice of parametrisations is based on our previous experience with the application of WRF in the region (Kirova et al., 2018; Barantiev et al., 2019).

The studied parameters wind speed (WS), wind direction (WD) and vertical wind speed $(W)$ are linearly interpolated to the sodar levels of measurements. The relationship between measured and modelled parameters is studied using statistical metrics. The strength of correlation is considered as very weak if $|r| \leq 0.2$, as weak if the $0.2<|r| \leq 0.4$, as moderate if the $0.4<|r| \leq 0.6$, as strong if the $0.6<|r| \leq$ 0.8 and very strong if $0.8<|r| \leq 1$. 

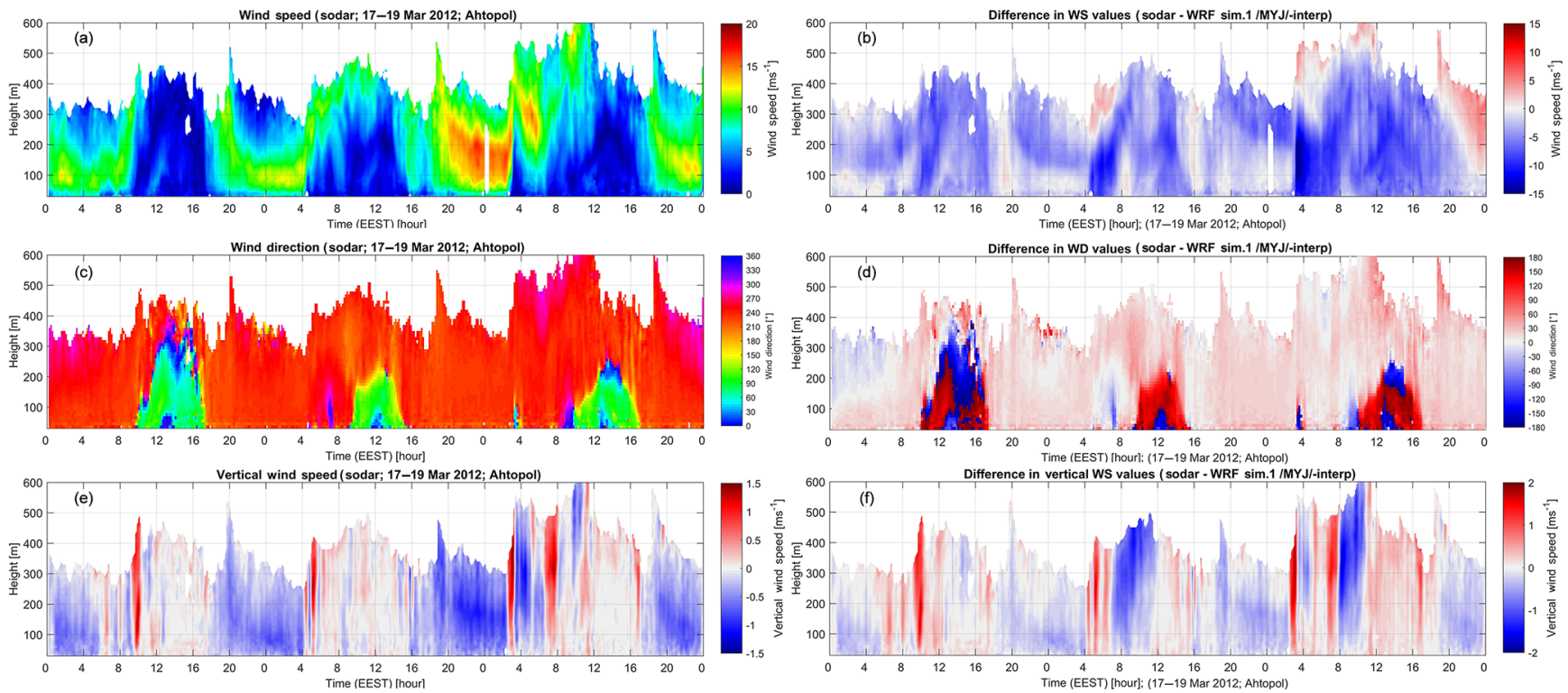

Figure 2. Observed (a, c, e) and difference (b, d, f) between observed and measured WS (a, b), WD (c, d) and W (e, f).
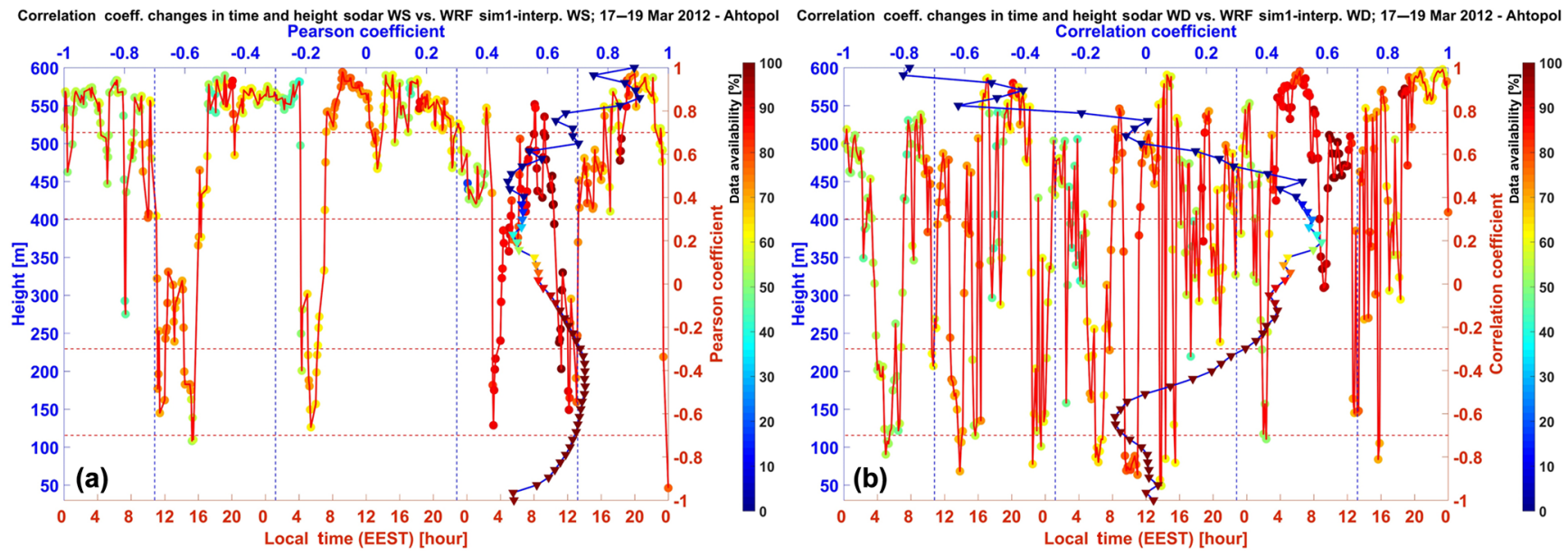

Figure 3. Spatial (top horizontal axis and blue line with multicolor triangles) and temporal (right vertical axis and red line with multicolor dots) values of the correlation coefficientsbetween observed and modelled WS (a) and WD (b). The color of the triangles and the dots correspond to the data availability (color bar on the right).

\section{Results}

The studied period 17-19 March 2012 includes four nocturnal periods with low-level jets (LLJ) located up to $300 \mathrm{~m}$ above the ground with maximum WS of about $15 \mathrm{~m} \mathrm{~s}^{-1}$ and followed by closed sea breeze (SB) cells with small spatial scales (up to $400 \mathrm{~m}$ including the calm zone), Fig. 2a. The period started with extreme winds from SW quarter which direction is reproduced by the model within $30^{\circ}$ and magnitude within $3 \mathrm{~m} \mathrm{~s}^{-1}$ with a positive bias of the WS. The $W$ is underestimated during the periods with extreme winds and overestimated during SB events.
As a quantitative measure of the ability of the model to reproduce the vertical and temporal structures of WS (Fig. 3a) and $W D$ (Fig. 3b) the correlation coefficients are calculated between observed and interpolated model data. Considering that the $\mathrm{WD}$ is a circular variable, the correlation coefficients are calculated using the approaches described in Berens (2009) and Jammalamadaka and Sengupta (2001). The vertical structure is studied using dataset including up to 58 values of $r$ (Fig. 3, blue lines referring to each sodar measurement level from 30 to $600 \mathrm{~m}$ at every $10 \mathrm{~m}$ ), calculated by using up to 432 pairs (time series at every $10 \mathrm{~min}$ for $72 \mathrm{~h}$ ). The temporal structure is studied using dataset including up to 432 values of $r$ (Fig. 3, red lines referring to each sodar 
Table 2. Statistical metrics for WS, WD and $W$ by WRF at ET Ahtopol for the period 17-19 March 2012.

\begin{tabular}{lrrrrrrrc}
\hline Parameter & COUNT & OBS & MOD & SD OBS & SD MOD & SDE & RMSE & $r$ \\
\hline${\text { WS }\left[\mathrm{m} \mathrm{s}^{-1}\right]}^{16560}$ & 6.727 & 10.251 & 3.598 & 3.541 & 3.117 & 4.705 & 0.62 \\
WD $\left[^{\circ}\right]$ & 16602 & 233.947 & 252.334 & 41.481 & 10.763 & 52.961 & 57.361 & 0.37 \\
$W\left[\mathrm{~m} \mathrm{~s}^{-1}\right]$ & 16125 & -0.125 & -0.096 & 0.354 & 0.334 & 0.420 & 0.421 & 0.25 \\
\hline
\end{tabular}

time series - every $10 \mathrm{~min}$ for $72 \mathrm{~h}$ ), calculated by using up to 58 pairs (sodar measurement level from 30 to $600 \mathrm{~m}$ at every $10 \mathrm{~m})$. The data availability involved in calculations of $r$ on both graphs in Fig. 3 is presented by coloured symbols (triangles for vertical structure where $100 \%$ corresponds to 52 values and dots for temporal structure where $100 \%$ corresponds to 432 values). The vertical structure of WS is satisfactory reproduced by the model - positive strong correlation for most of the heights except the first $50 \mathrm{~m}$ and the layer between 300 and $500 \mathrm{~m}$ where $0.4<|r| \leq 0.6$ and very strong correlation above $550 \mathrm{~m}$ except $590 \mathrm{~m}$ where the correlation is strong. The temporal structure of the WS is reproduced with very week and weak correlation in $19 \%$ of all observational hours. The negative $r$ values (15\% of all observational hours) associated with a sharp change in the wind direction around the onset and ceasing of the SB and with strong (18\%) and very strong (44\%) of all observational hours. The values of $r$ for the WD are within range $0.4<|r| \leq 0.6$ for $35 \%$ of all measurements levels; with positive values of $r$ in $74 \%$ of all observational times, in $18 \%$ the correlation is moderate, strong in $17 \%$ and very strong in $20 \%$.

In addition to the vertical and temporal correlations coefficients of the studied parameters some basic statistical metrics are given in Table 2 for all data (number of data - COUNT; mean values of observations and model - OBS, MOD; the standard deviation of observations and model - $\mathrm{SD}_{\mathrm{OBS}}$, $\mathrm{SD}_{\mathrm{MOD}}$; the standard deviation of error-SDE; the root mean square error - RMSE; the correlation coefficient $-r$ ). The WRF model overestimates the observed WS with about $52 \%$ (Normalized Mean Bias) with about $3.5 \mathrm{~m} \mathrm{~s}^{-1}, W$ is underestimated with about $23 \%$ and negative bias in WD is $18.4^{\circ}$. The lack of SB events in the model simulations leads to the most significant difference in SD of WD compared to the WS and $W$. For this simulation, WS has strong correlation (0.62) while $W$ has weak correlation $(0.25)$.

\section{Conclusions}

The presence of extreme winds in combination with local circulations in coastal region is investigated using sodar data and numerical simulations. The simulations with MYJ ABL scheme capture the observed durations of the nocturnal extreme winds closely but the sea breeze events are not reproduced by the model. In general, the model overestimates the WS (probably due to overestimated values of WS in the FNL data) which could be a reason for the lack of SB events considering the predominant synoptic SW flow during the studied period. The temporal (44\% of all observations) and vertical (31 levels) structure of the WS is simulated by the model respectively with very strong and strong correlation. The simulated WD vertical structure has the lowest correlation coefficients. The highest value of correlation coefficient from all data is obtained for WS while the lowest - for $W$. Evaluation of the model results was possible using comprehensive sodar data which is a powerful tool for revealing the potential of meso meteorological models for air quality and wind energy proposes.

Data availability. The WRF numerical simulation data and the acoustic sounding data of the coastal PBL at town of Ahtopol for the study period are available on request. Please contact the team leader of the REPLICA project at: dbarantiev@ cawri.bas.bg.

Author contributions. DYB devised the project, the main conceptual ideas and developed the theoretical framework. DYB, HIK and OAG contributed to the design and implementation of the research. DYB performed the analysis of the sodar data. HIK performed the numerical simulations for the study period. DYB performed the correlation coefficients and statistical output calculations. DYB designed the Figs. 2 and 3. HIK designed the Fig. 1 with support from DYB. All authors discussed the results. DYB wrote the final version of the manuscript with support from HIK.

Competing interests. The authors declare that they have no conflict of interest.

Special issue statement. This article is part of the special issue "19th EMS Annual Meeting: European Conference for Applied Meteorology and Climatology 2019". It is a result of the EMS Annual Meeting: European Conference for Applied Meteorology and Climatology 2019, Lyngby, Denmark, 9-13 September 2019.

Financial support. This research has been supported by the National Science Fund of Bulgaria (grant no. DM-14/1-20.12.2020).

Review statement. This paper was edited by Sven-Erik Gryning and reviewed by two anonymous referees. 


\section{References}

Atanassov, E., Gurov, T., Karaivanova, A., Ivanovska, S., Durchova, M., and Dimitrov, D.: On the Parallelization Approaches for Intel Mic Architecture, edited by: Todorov, M. D., in: vol. 070001, AIP Conference Proceedings: 8th International Conference for Promoting the Application of Mathematics in Technical and Natural Sciences - AMiTaNS'16, 22-27 June 2016, Albena, Bulgaria, 2016.

Barantiev, D., Novitsky, M., and Batchvarova, E.:Meteorological Observations of the Coastal Boundary Layer Structure at the Bulgarian Black Sea Coast, Adv. Sci. Res., 6, 251-259, https://doi.org/10.5194/asr-6-251-2011, 2011.

Barantiev, D., Batchvarova, E., and Novitsky, M.: Exploration of the Coastal Boundary Layer in Ahtopol through Remote Acoustic Sounding of the Atmosphere, in: Section: Physics of Earth, Atmosphere and Space Edn., Conference Proceedings: 2nd National Congress on Physical Sciences, Heron Pres, Sofia, Bulgaria, 2013.

Barantiev, D., Batchvarova, E., and Novitsky, M.: Breeze Circulation Classification in the Coastal Zone of the Town of Ahtopol Based on Data from Ground Based Acoustic Sounding and Ultrasonic Anemometer, Bulgar. J. Meteorol. Hydrol., 22, 3-25, 2017.

Barantiev, D., Kirova, H., Gueorguiev, O., and Batchvarova, E.: Mesoscale Modeling of Extreme Coastal Weather against Sodar Data - a Case Study, edited by: Mishonov, T. M. and Varonov, A. M., in: Vol. 2075, AIP Conference Proceedings, 10th Jubilee Conference of the Balkan Physical Union, Sofia, Bulgaria, 2019.

Batchvarova, E. and Gryning, S. E.: Wind Climatology, Atmospheric Turbulence and Internal Boundary-Layer Development in Athens During the Medcaphot-Trace Experiment, Atmos. Environ., 32, 2055-2069, https://doi.org/10.1016/S13522310(97)00422-6, 1998.

Berens, P.: Circstat: A Matlab Toolbox for Circular Statistics, J. Stat. Softw., 31, 1-21, https://doi.org/10.18637/jss.v031.i10, 2009.

Gryning, S.-E., Batchvarova, E., Floors, R. R., Peña, A., Brümmer, B., Hahmann, A. N., and Mikkelsen, T.: Long-Term Profiles of Wind and Weibull Distribution Parameters up to $600 \mathrm{M}$ in a Rural Coastal and an Inland Suburban Area, Bound.-Lay. Meteorol., 150, 167-184., https://doi.org/10.1007/s10546-013-9857-3, 2014.
Gryning, S.-E., Floors, R., Peña, A., Batchvarova, E., and Brümmer, B.: Weibull Wind-Speed Distribution Parameters Derived from a Combination of Wind-Lidar and Tall-Mast Measurements over Land, Coastal and Marine Sites, Bound.-Lay. Meteorol., 159, 329-348, https://doi.org/10.1007/s10546-015-0113-x, 2016.

IPCC: Climate Change 2001: The Scientific Basis, in: Contribution of Working Group I to the Third Assessment Report of the Intergovernmental Panel on Climate Change, edited by: Houghton, J. T., Ding, Y., Griggs, D. J., Noguer, M., van der Linden, P. J., Dai, X., Maskell, K., and Johnson, C. A., Cambridge University Press, Cambridge, UK and New York, NY, USA, 2011.

Jammalamadaka, S. R. and Sengupta, A.: Topics in Circular Statistics, edited by: Rao, M. M., in: Vol. 5, Series on Multivariate Analysis, World Scientific, available at: https://books.google.bg/ books?id=sKqWMGqQXQkC (last access: 24 June 2020), 2001.

Kirova, H., Barantiev, D., and Batchvarova, E.: Evaluation of Mesoscale Modelling of a Closed Breeze Cell against Sodar Data, in: Air Pollution Modeling and Its Application XXV, vol. Springer Proceedings in Complexity, edited by: Mensink, C. and Kallos, G., Springer, 151-155, https://doi.org/10.1007/9783-319-57645-9_24, 2018.

Novitsky, M., Kulizhnikova, L., Kalinicheva, O., Gaitandjiev, D., Batchvarova, E., Barantiev, D., and Krasteva, K.: Characteristics of Speed and Wind Direction in Atmospheric Boundary Layer at Southern Coast of Bulgaria, Russ. Meteorol. Hydrol., 37, 159164, 2012.

Petrović, V. and Bottasso, C. L.: Wind Turbine Optimal Control During Storms, in: Vol. 524, The Science of Making Torque from Wind 2014 (TORQUE 2014) IOP Publishing Ltd, Copenhagen, Denmark, 2014.

Skamarock, W. C., Klemp, J. B., Dudhia, J., Gill, D. O., Barker, D. M., Duda, M. G., Huang, X.-Y., Wang, W., and Powers, J. G.: A Description of the Advanced Research Wrf Version 3, in: Vol. NCAR Technical Note, vol. NCAR/TN-475+STR. edited by: Publications Office of NCAR. Translated by National Center for Atmospheric Research (NCAR) Mesoscale and Microscale Meteorology Division, NCAR Scientific Divisions, Boulder, Colorado, USA, 2008. 